\title{
Enantiospecific Molecular Fingerprinting Using Potential-Modulated Surface- Enhanced Raman Scattering to Achieve Label-Free Chiral Differentiation
}

Shi Xuan Leonga, Charlynn Sher Lin Koha, Howard Yi Fan Simª, Yih Hong Lee ${ }^{a}$, Xuemei Hanª, Gia Chuong Pang-Quanga, Xing Yi Ling*

${ }^{a}$ Division of Chemistry and Biological Chemistry, School of Physical and Mathematical Sciences, Nanyang Technological University, 21 Nanyang Link, Singapore 637371.

*To whom correspondence should be addressed. Email: xyling@ntu.edu.sg 
(A) $\mathrm{AgCl}$
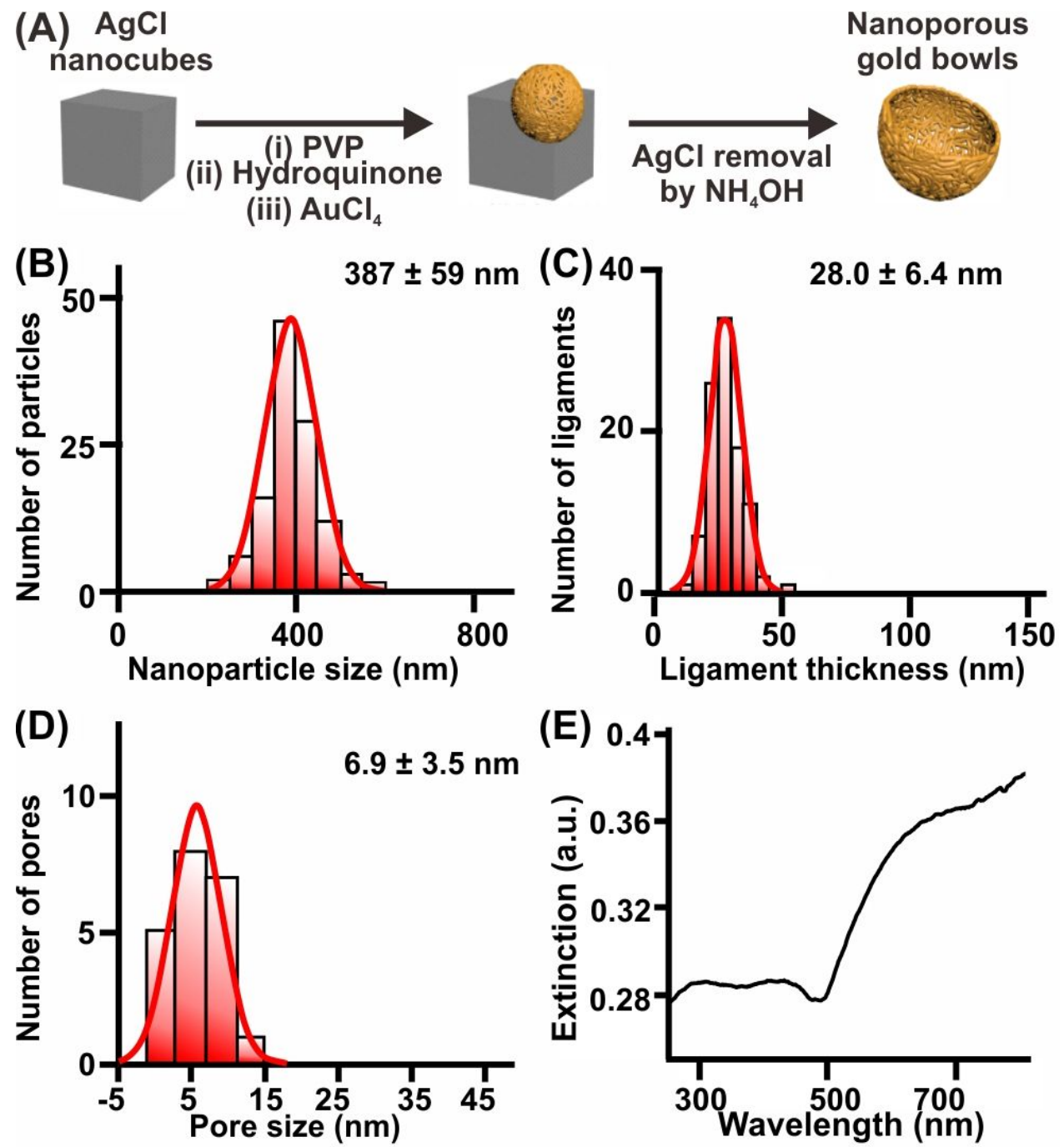

Figure S1. (A) Schematic illustrating the formation of nanoporous gold bowls (NPGBs). (B - D) Nanoparticle size, ligament thickness and pore size distribution curves of as-synthesized NPGBs. (E) UV-vis extinction spectrum of as-synthesized NPGBs. 
Supporting Information 1. Calculation of enhancement factor (EF)

The enhancement factor is calculated by using the equation below:

$$
E F=\frac{I_{S E R S}}{I_{\text {Normal }}} \times \frac{N_{\text {Normal }}}{N_{\text {SERS }}}
$$

We choose the peak at $1101 \mathrm{~cm}^{-1}$ of the 4-methylbenzenthiol (MBT) normal Raman spectrum and the corresponding peak at $1080 \mathrm{~cm}^{-1}$ of the MBT SERS spectrum.
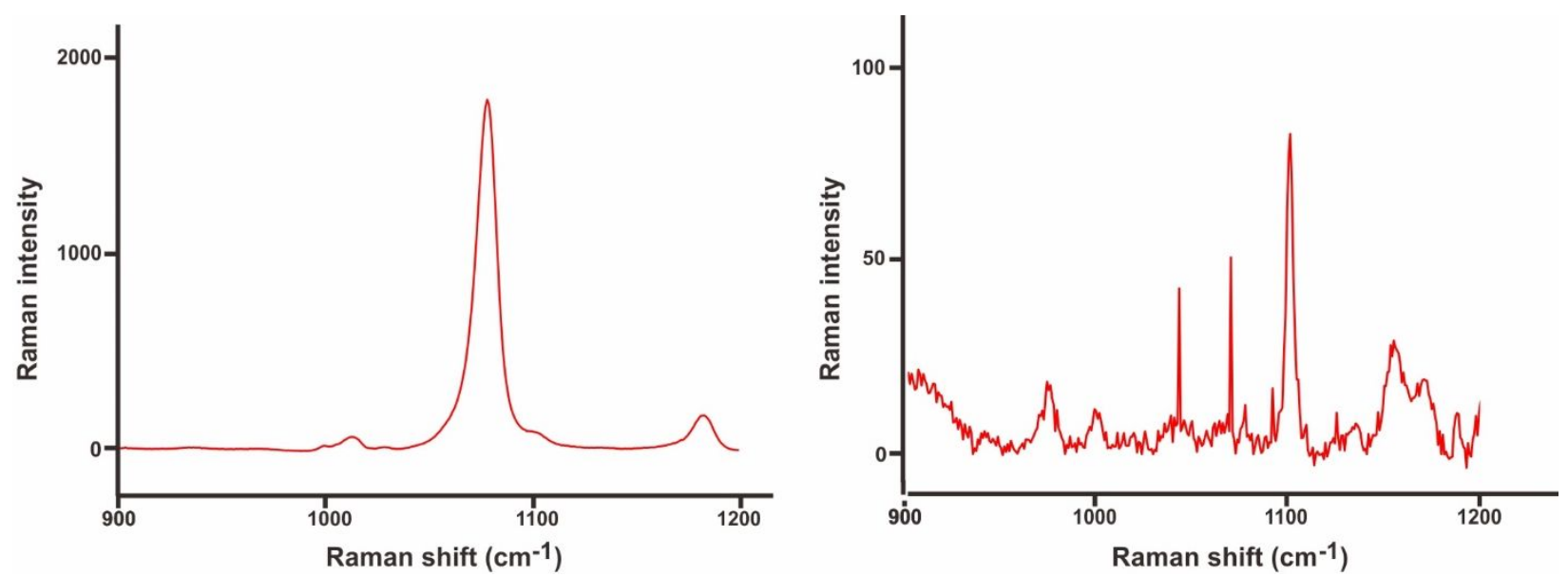

Figure S2. SERS (left) and normal Raman (right) spectra of MBT.

$\mathrm{I}_{\text {Normal }}=82.8$ counts $/ 500 \mathrm{~s}=0.166 \mathrm{cps}$ (based on MBT solid; measured using 50X objective lens, line scan, $500 \mathrm{~s}$ integration time)

$\mathrm{N}_{\text {Normal }}=$ number of molecules within the measured laser spot

$$
\begin{aligned}
& =\frac{\text { Volume of laser spot } \times \text { density of MBT }}{\text { MW of MBT }} \times \text { Avogadro's number } \\
& =\frac{\pi \times \mathrm{x} \times \mathrm{y} \times \mathrm{z} \times 1.0 \mathrm{gcm}^{-3}}{124.21 \mathrm{gmol}^{-1}} \times 6.022 \times 10^{23}\left(\mathrm{x}=6.25 \times 10^{-5} \mathrm{~cm}, \mathrm{y}=8.35 \times 10^{-5} \mathrm{~cm}, \mathrm{z}=6.77 \times\right. \\
& \left.10^{-3} \mathrm{~cm}\right) \\
& =5.3786 \times 10^{11} \text { molecules }
\end{aligned}
$$

$\mathrm{I}_{\mathrm{SERS}}=1080.8$ (on NPGB; measured using 50X objective lens, line scan, 5s integration time)

To estimate $\mathrm{N}_{\text {SERS }}$, we first estimate the number of layers of NPGB on an Au working electrode. We approximate the NPGB shape to be spherical.

Volume of NPGB used = Mass of NPGB used / density of Au

$$
\begin{aligned}
& =0.02 \mathrm{mg} / 19.3 \mathrm{gcm}^{-3} \\
& =1.0363 \times 10^{-6} \mathrm{~cm}^{3}
\end{aligned}
$$


Thickness of NPGB layer $=\frac{1.0363 \times 10^{-6} \mathrm{~cm}^{3}}{\pi \times 0.1^{2} \mathrm{~cm}^{2}}=330.03 \mathrm{~nm}$

Number of NPGB layers $=330.03 \mathrm{~nm} / 387 \mathrm{~nm}=1$ layer

Surface area of one NPGB $=74.94 \times 10^{4} \mathrm{~nm}^{2}$

$\mathrm{N}_{\mathrm{SERS}}=$ number of MBT molecules on one NPGB $\times$ number of NPGBs in laser spot volume

$$
\begin{aligned}
& =\frac{74.94 \times 10^{4} \mathrm{~nm}^{2}}{2.3 \times 2.3 \AA^{2} / \text { molecule }} \times \text { number of NPGB layers } \times\left(\frac{\text { laser spot area }}{\text { surface area of } 1 \mathrm{NPGB}}\right) \\
& =\frac{74.94 \times 10^{4} \mathrm{~nm}^{2}}{0.0529 \mathrm{~nm}^{2} / \text { molecule }} \times 1 \times\left(\frac{\pi \times 625 \mathrm{~nm} \times 835 \mathrm{~nm}}{\pi \times\left(\frac{387}{2}\right)^{2} \mathrm{~nm}^{2}}\right) \\
& =1.9745 \times 10^{8}
\end{aligned}
$$

$\mathrm{EF}=\frac{1080.8}{0.166} \times \frac{5.3786 \times 10^{11}}{1.9745 \times 10^{8}}=1.77 \times 10^{7}$ 

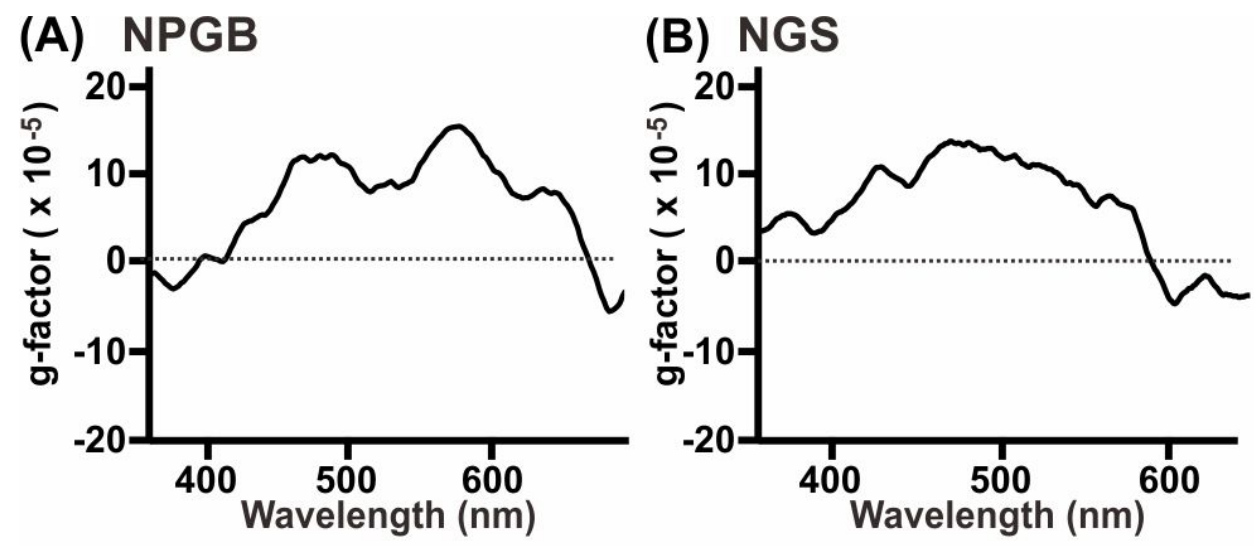

Figure S3. CD anisotropy g-factors at different wavelengths for (A) nanoporous gold bowls (NPGB) and (B) nanoporous gold spheres (NGS).

We calculated the CD anisotropy g-factor based on the formula $g=\frac{\Delta \varepsilon}{\varepsilon}=\frac{A_{L}-A_{R}}{A}$, where $\varepsilon$ is the extinction coefficient, $A_{L}-A_{R}$ is the differential absorbance of circularly polarized light and $A$ is the absorbance of non-polarized light. ${ }^{1}$ The experimentally obtained CD ellipticity $\theta$ in mdeg is converted to $\Delta \mathrm{A}$ using the relationship $\theta(\mathrm{mdeg}) \approx 32980 \Delta A \cdot{ }^{2}$ We note that exceptionally large g-factors from $10^{-1}$ to $10^{-2}$ have been reported using chiral ligands such as chiral micelles and chiral amino acids/DNA motifs to attain high chiroptical activity via chirality transfer or chirality imprinting. ${ }^{3-4}$ Optical activity can also be enhanced by introducing structural CD in the form of well-oriented assemblies of discrete nanoparticles into chiral configurations, e.g. twisted nanorod assemblies. ${ }^{5-7}$ In our case, the optical activity of our NPGs originates from local symmetry breaking at defect sites, which occurs on smaller length-scales, with no chiral ligands/motifs involved, and thus only moderate g-factors (weak CD signals) are observed. Nonetheless, the observed presence of chirality in our NPG nanostructures, notably with high reproducibility as illustrated in Figure S4, is remarkable because it is notoriously hard to synthesize chiral colloidal nanoparticles without employing chiral ligands. 
Different NPGB batches

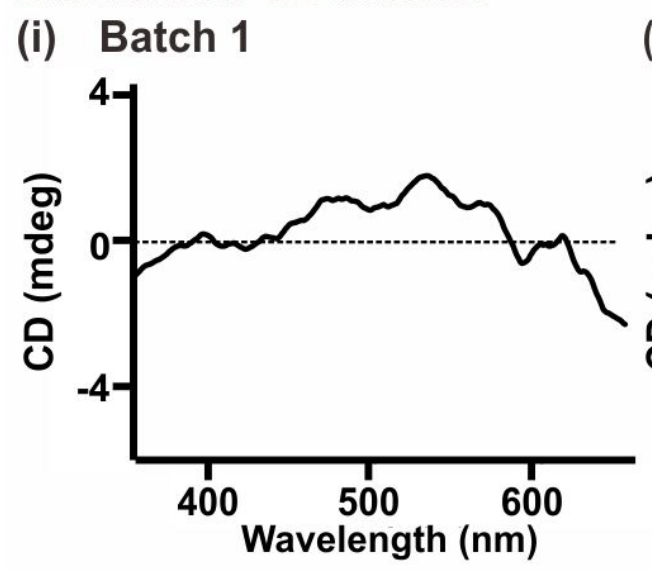

(ii) Batch 2

(iii) Batch 3
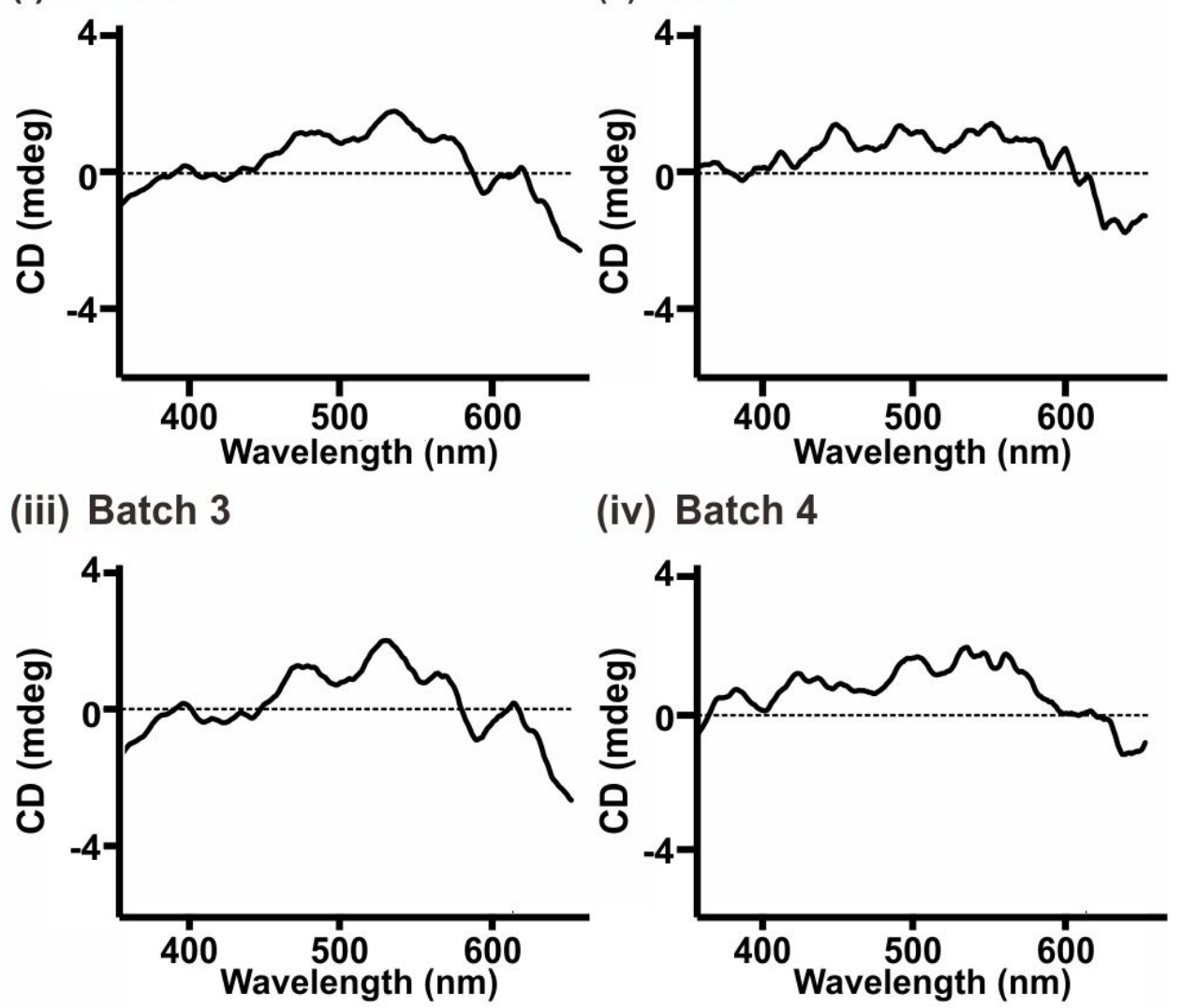

(iv) Batch 4

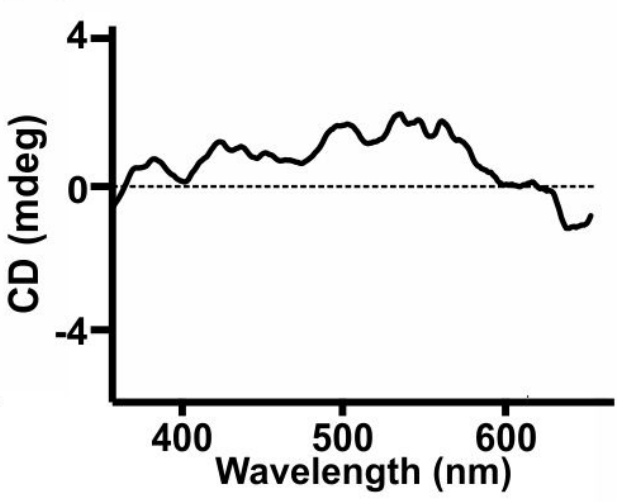

Figure S4. CD signals from different NPGB batches with ligament thickness of $\sim 28 \mathrm{~nm}$. 


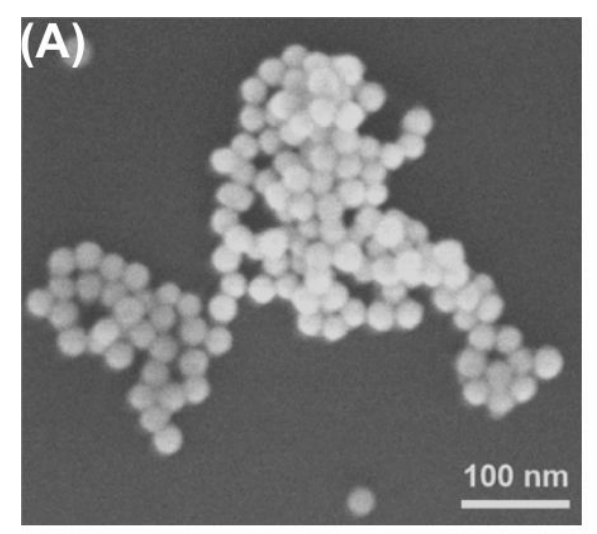

(B) Smooth $27.0 \mathrm{~nm}$ Au NPs

(C) PVP only
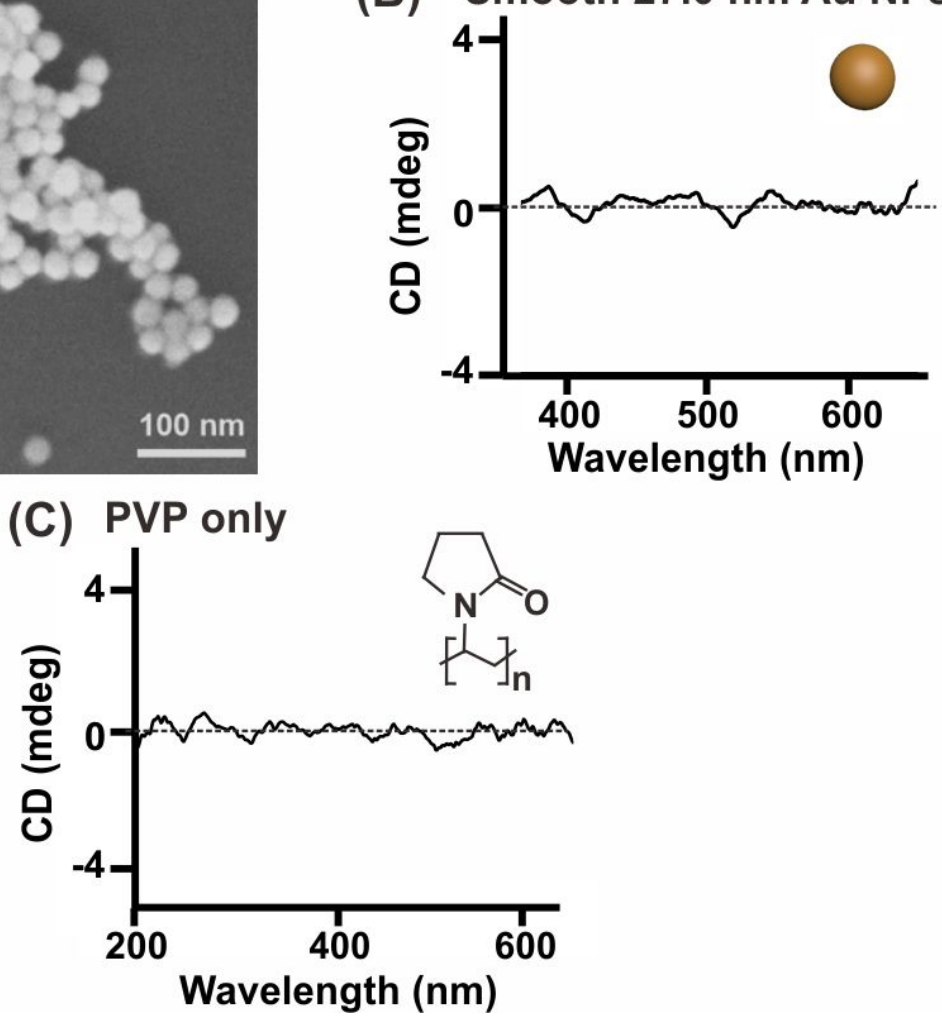

Figure S5. (A, B) SEM image and circular dichroism spectra of smooth spherical Au NPs. (C) Circular dichroism spectrum of PVP only, which is employed as a capping agent during NPGB synthesis. 
Pb UPD stripping curves (smooth Au NPs)
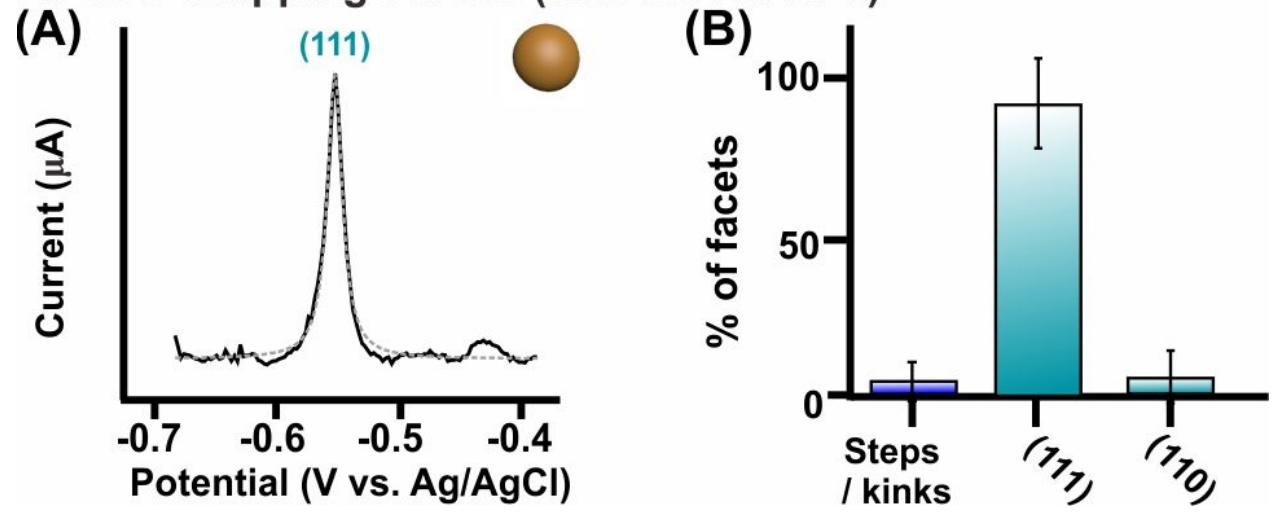

Figure S6. Pb underpotential deposition studies using smooth spherical Au NPs. (A) Deconvolution of the stripping waves into the component peaks and (B) relative $\%$ of each facet/defect. Average and standard deviations are obtained from 3 measurements. 


\section{Supporting Information 2}

The Pb UPD cyclic voltammograms of NPGB exhibit two distinct anodic stripping peaks at $\sim-0.58 \mathrm{~V}$ and $\sim-0.42 \mathrm{~V}$, which can be indexed to the (111) and (110) facets respectively. We also observe two shoulders on the left and right of the (111) peak at $\sim-0.66 \mathrm{~V}$ and $\sim-0.53 \mathrm{~V}$, which correspond to contributions from surface step and kink sites and (100) facets, respectively. It is of note that the full width at half maximum values of the deconvoluted peaks differ between the facets because the potential ranges for $\mathrm{Pb}$ dissolution from different facets are different. ${ }^{8}$ Our observed peak separations between the different facets are consistent with the literature values. To estimate the proportions of different facets, we de-convoluted the anodic peaks and compared the peak intensities. 3 different measurements were used to determine the average $\%$ and standard deviation.

Table S1. Table of \% facets of NPGB estimated from Pb UPD studies.

\begin{tabular}{lcccc}
\hline & Steps/kink sites & $\mathbf{( 1 1 1 )}$ facets & $\mathbf{( 1 0 0 )}$ facets & (110) facets \\
\hline \% proportion & $18.1 \pm 4.6$ & $26.6 \pm 2.7$ & $15.2 \pm 5.4$ & $40.2 \pm 2.5$ \\
\hline
\end{tabular}


Table S2. Comparison of D- and L-TRP oxidation peak intensity using NPGB-modified electrodes.

TRP oxidation peak current $(\boldsymbol{\mu A})$

\begin{tabular}{lccc}
\hline & D-TRP & L-TRP & \% difference \\
Electrode 1 & 216 & 182 & 18.8 \\
Electrode 2 & 188 & 171 & 10.3 \\
Electrode 3 & 211 & 188 & 12.1 \\
& \multicolumn{2}{c}{ Average \% difference } & 13.7 \\
\hline
\end{tabular}

It is of note that we used the second scan cycle throughout the calculations. \% difference is obtained using the following equation:

$$
\% \text { difference }=\left(\frac{\text { Peak current difference }}{\text { Peak current of D }-T R P}\right) \times 100 \%
$$




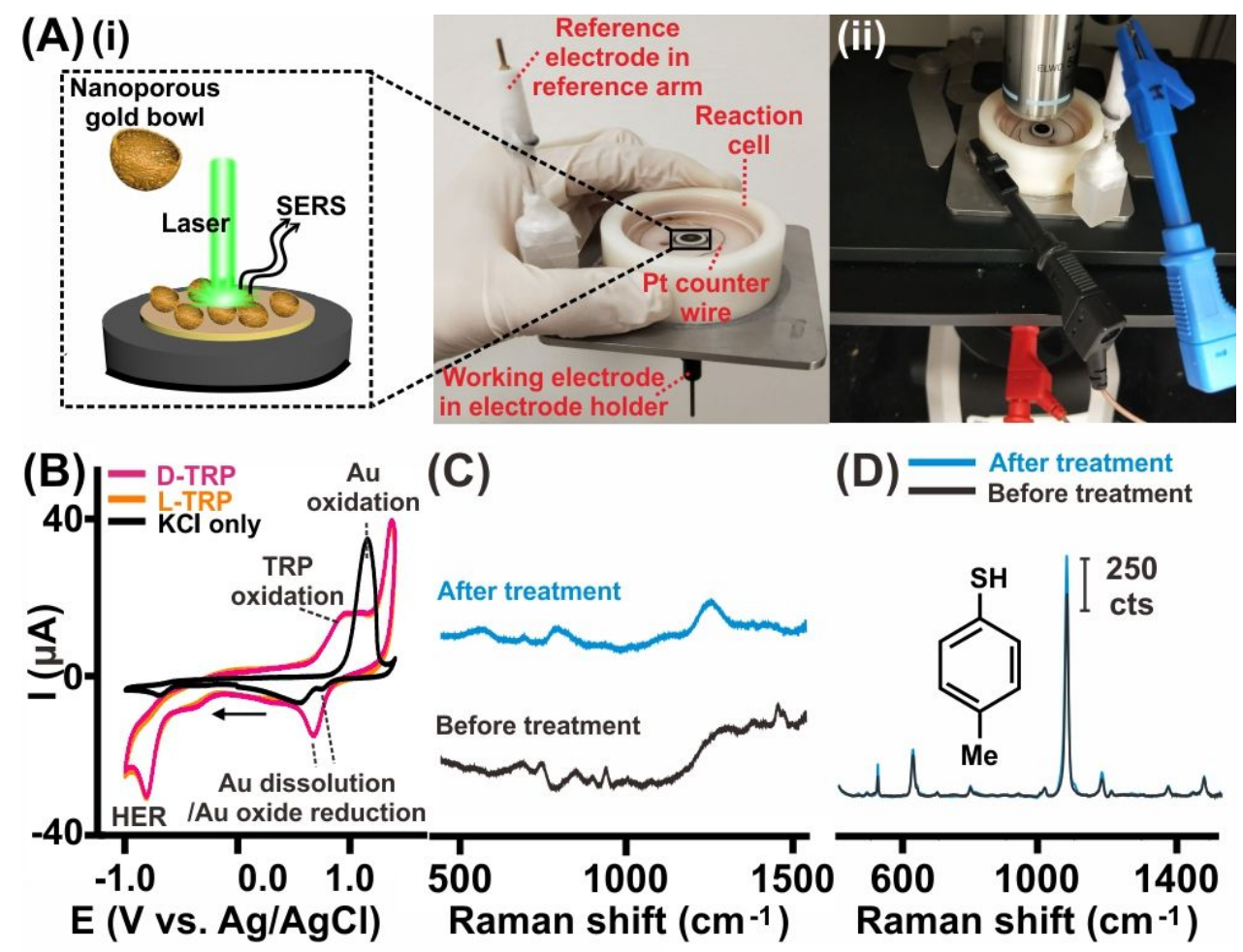

(E) After treatment

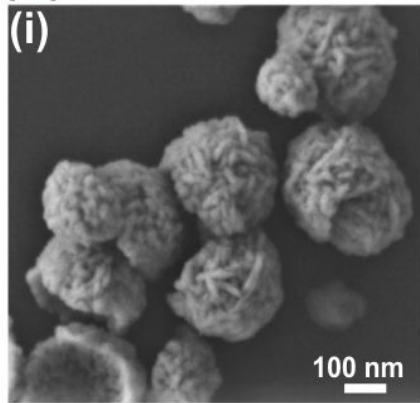

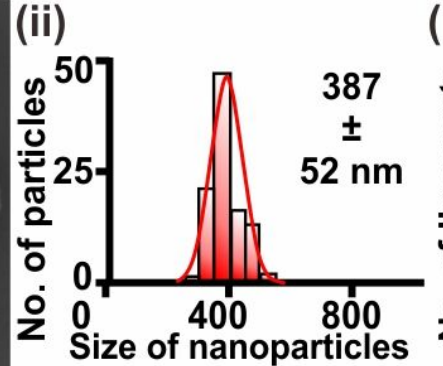

$(\mathrm{nm})$ (iii)

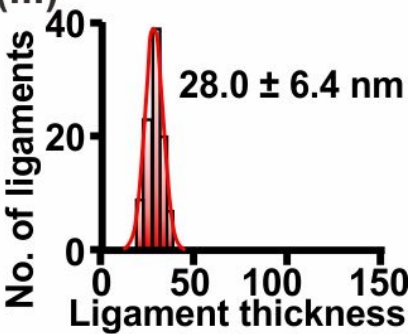

(nm)

Figure S7. (A) The customized EC-SERS cell, with the reference, counter and working electrode labelled and (ii) the set-up for the EC-SERS differentiation. The EC-SERS cell is placed on the Raman stage such that the laser spot is focused on the NPG-coated electrode surface. (B) Cyclic voltammograms of unmodified Au electrode with and without L- or D-TRP in $0.1 \mathrm{M} \mathrm{KCl}$ as supporting electrolyte. The $\mathrm{CV}$ recorded in $0.1 \mathrm{M} \mathrm{KCl}$ only is scaled by 0.1 for easy comparison. Corresponding (C) NPGB SERS spectra, (D) 4-methylbenzenthiol (MBT, test probe) SERS spectra and respective (Ei - iii) SEM image, nanoparticle size and ligament size distribution curve before and after $\mathrm{O}_{2}$ plasma treatment.

Cyclic voltammograms measured in the absence and presence of TRP analyte show no significant changes in cathodic currents within the chosen potential window of $0.0 \mathrm{~V}$ to $-0.6 \mathrm{~V}$, indicating that the target analyte does not undergo electrochemical reduction within our chosen potential window. The reduction peak at $-0.8 \mathrm{~V}$ is attributed to hydrogen evolution reaction (Figure S7A). The oxidation peak at $\sim 1.2 \mathrm{~V}$ and the coupled reduction peaks at $0.8 \mathrm{~V}$ and $0.6 \mathrm{~V}$ respectively can be indexed to Auassociated reactions including Au dissolution due to complex formation with the $\mathrm{Cl}^{-}$ions and $\mathrm{Au}$ oxide 
formation/reduction. In the presence of TRP, the only TRP-related peak is the oxidation peak at $\sim 0.92$ $\mathrm{V}$, which is markedly absent without TRP addition, and can hence be univocally indexed to the irreversible oxidation of TRP. 4-MBT is used as test probe to evaluate NPGB SERS performance before and after pretreatment. Both spectra show characteristic MBT Raman bands with comparable intensities, indicating that the pretreatment does not affect the SERS capability of NPGB. 
Table S3. TRP peak assignment without and with negative applied potential, $\mathrm{V}_{\text {applied. }}$

\begin{tabular}{|c|c|c|c|}
\hline \multicolumn{2}{|c|}{$\begin{array}{c}\text { Experimental Raman } \\
\text { shift }\left(\mathrm{cm}^{-1}\right)\end{array}$} & \multirow[t]{2}{*}{$\begin{array}{l}\text { Literature values } \\
\qquad\left(\mathrm{cm}^{-1}\right)\end{array}$} & \multirow[t]{2}{*}{ Peak assignment ${ }^{9-11}$} \\
\hline $\begin{array}{l}\text { Without } \\
\text { V }_{\text {applied }}\end{array}$ & $\mathbf{V}_{\text {applied }}$ & & \\
\hline- & 430 & 437 & Indole ring deformation \\
\hline- & $\begin{array}{l}643 \text { (only } \\
\text { for D-TRP) }\end{array}$ & 649 & Indole $\mathrm{CH}$ bending \\
\hline- & $\begin{array}{l}731 \text { (only } \\
\text { for D-TRP) }\end{array}$ & 734 & Benzene deformation; CN stretch \\
\hline 757 & & 757 & Indole symmetric breathing \\
\hline- & 778 & 783 & $\mathrm{COO}^{-}$scissoring; $\mathrm{C}-\mathrm{C}$ stretching \\
\hline- & 852 & & $\mathrm{CN}$ stretching; $\mathrm{NH}_{3}{ }^{+}$bending \\
\hline 877 & & 877 & Indole $\mathrm{NH}$ bending \\
\hline- & 933 & 923 & $\mathrm{NH}_{3}{ }^{+}$rocking \\
\hline 1012 & $\begin{array}{c}1010 \\
999\end{array}$ & 1012 & Indole asymmetric breathing \\
\hline 1342 & 1358 & 1348 & Fermi resonance interaction of the indole ring \\
\hline 1374 & & 1362 & $\begin{array}{l}\text { CN stretching with the combination bands of } \\
\text { out-of-plane bending }\end{array}$ \\
\hline 1425 & 1425 & 1425 & $\mathrm{COO}^{-}$stretching \\
\hline 1449 & 1449 & 1442 & Indole and benzene stretching \\
\hline
\end{tabular}


(A) $\bar{\delta} \mathrm{CH}$ (ind)

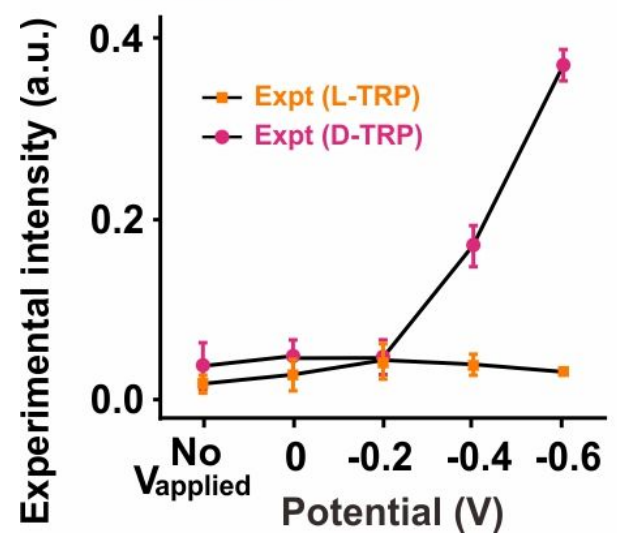

(B) $\omega_{\mathrm{CH}(\mathrm{R})}$

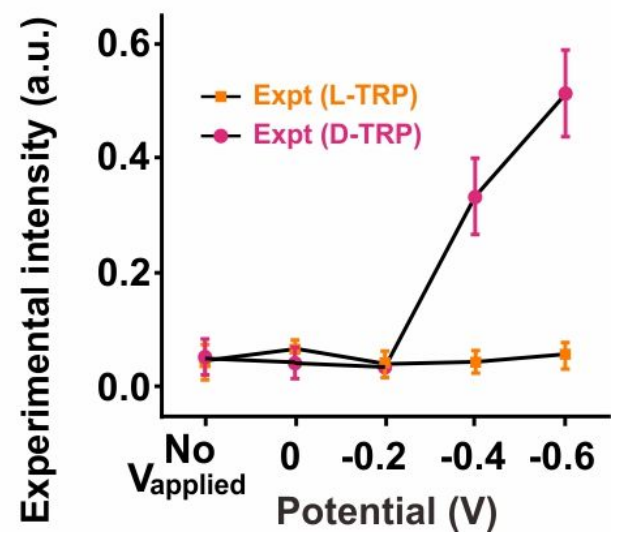

Figure S8. Potential-dependent variations in the experimental peak intensities of (A) out-of-plane indole $\mathrm{CH}$ bending, $\delta_{\mathrm{CH}(\text { indole) }}$ and (B) out-of-plane benzene $\mathrm{CH}$ wagging $\omega_{\mathrm{CH}(\mathrm{R})}$ vibrational modes, normalized with the intensity of the $\beta_{\text {symm(ind) }}$ mode at $757 \mathrm{~cm}^{-1}$.

The experimental peaks at 643,731 and $778 \mathrm{~cm}^{-1}$ indexed to out-of-plane indole $\mathrm{CH}$ bending $\delta_{\mathrm{CH}(\text { indole) }}$, out-of-plane benzene $\mathrm{CH}$ wagging $\omega_{\mathrm{CH}(\mathrm{R})}$ and $\mathrm{COO}^{-}$scissoring $\alpha_{(\mathrm{COO}-)}$, respectively, are in good agreement with the simulated peaks observed at 592, 761 and $804 \mathrm{~cm}^{-1}$ (Figure 3A). The deviation of Raman peak shifts between experimental and simulated results is possiby due to the differences in exact molecule structure orientation. In addition, our single molecule simulation does not account for the overall coverage effects of multiple analyte molecules near the plasmonic surface. ${ }^{12-13}$ It is of note that the $\mathrm{Au}_{6}$ cluster used in our DFT simulations does not fully represent the chiral facets on NPGB. Nonetheless, by simulating different adsorption configurations on the $\mathrm{Au}_{6}$ cluster, we can still obtain useful molecular insight to derive the preferred adsorption configuration of each TRP near the NPGB adsorption site, in good agreement with our experimental spectra. 
(A) Reverse anodic sweep from $-0.6 \mathrm{~V}$ back to $0.0 \mathrm{~V}$

(i)

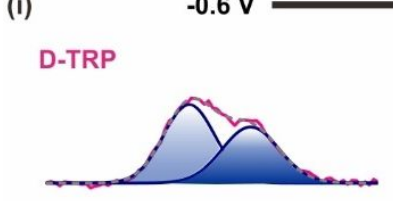

(ii)
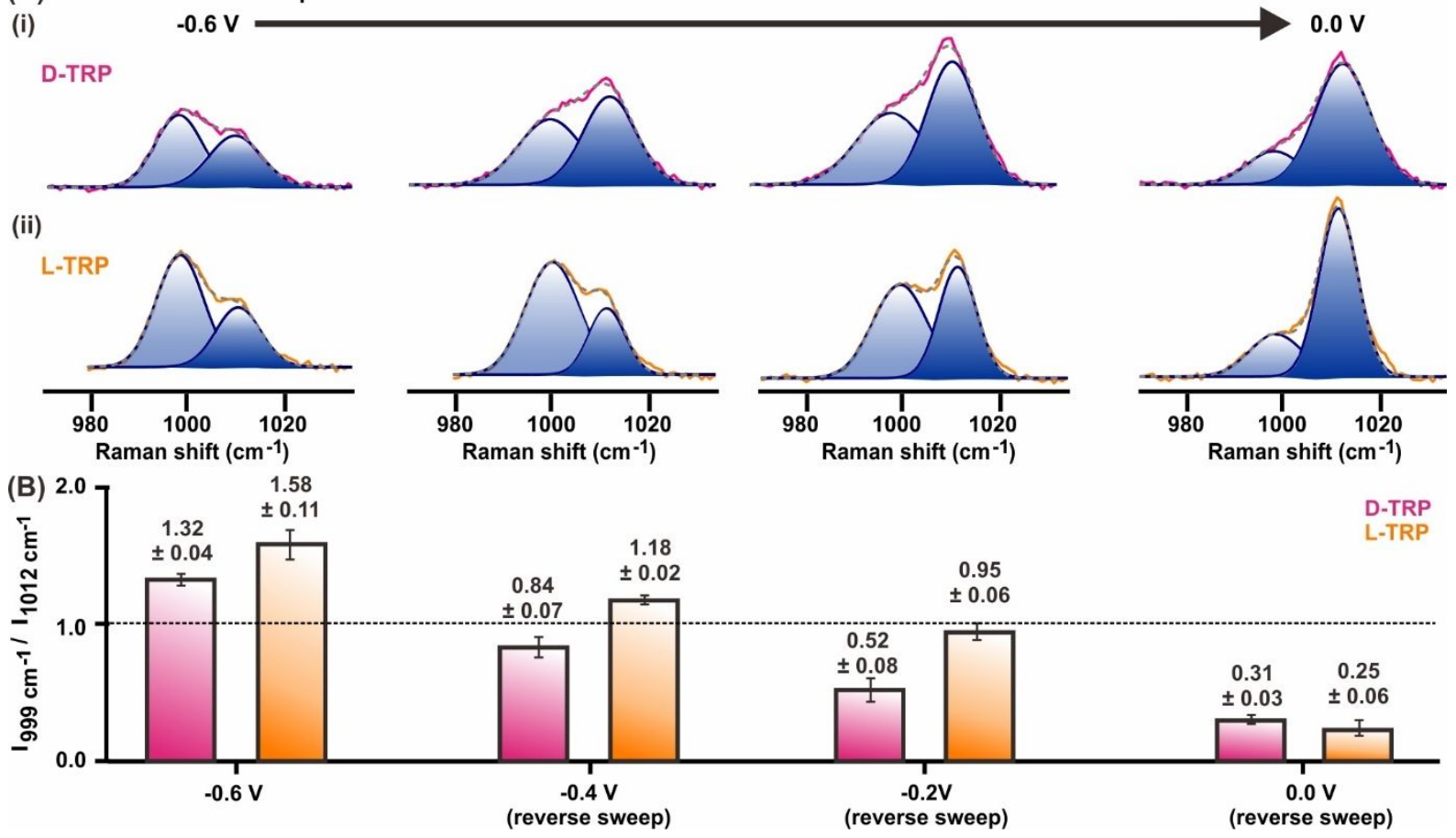

Figure S9. Reverse anodic sweep from -0.6 V back to 0.0 V. (A) Deconvoluted Raman bands of 999 and $1012 \mathrm{~cm}^{-1}$ peaks for (i) D- and (ii) L-TRP. (B) Corresponding $\mathrm{I}_{999 \mathrm{~cm}-1} / \mathrm{I}_{1012 \mathrm{~cm}-1}$ peak intensity ratios. Average and standard deviations are obtained from 5 SERS spectra. 
Supporting Information 3. Additional discussion on changes in $\mathrm{I}_{999 \mathrm{~cm}-1} / \mathrm{I}_{1012 \mathrm{~cm}-1}$ peak intensity ratio upon reversal of potential.

The rate of decrease in $\mathrm{I}_{999 \mathrm{~cm}-1} / \mathrm{I}_{1012 \mathrm{~cm}-1}$ peak intensity ratio as the potential is reversed from $-0.6 \mathrm{~V}$ to $0.0 \mathrm{~V}$ is calculated as follows:

Rate of decrease $=\frac{\text { Ratio }_{\text {initial }}-\text { Ratio }_{V}}{\text { Ratio }_{\text {initial }}} \times 100 \%$

where Ratio $_{\text {initial } \mathrm{V}}$ and Ratio $_{\mathrm{V}}$ refers to the peak intensity ratio at the initial $\mathrm{V}_{\text {applied }}$ and the subsequent $\mathrm{V}_{\text {applied }}$ on the reverse potential sweep respectively.

Table S4. Table of rate of decrease of $\mathrm{I}_{999 \mathrm{~cm}-1} / \mathrm{I}_{1012 \mathrm{~cm}-1}$ peak intensity ratio.

\begin{tabular}{cccc}
\hline & $\mathbf{- 0 . 6 V}$ to $-0.4 \mathrm{~V}$ & $\mathbf{- 0 . 4} \mathrm{V}$ to $\mathbf{- 0 . 2} \mathrm{V}$ & $\mathbf{- 0 . 2 ~ V ~ t o ~ 0 . 0 ~ V}$ \\
\hline L-TRP & $-25 \%$ & $-20 \%$ & $-74 \%$ \\
D-TRP & $-36 \%$ & $-38 \%$ & $-40 \%$ \\
\hline
\end{tabular}

For both TRP, the ratios decrease as $\mathrm{V}_{\text {applied }}$ decreases back to $0 \mathrm{~V}$ due to possible desorption. However, the ratio of D-TRP decreases at a faster rate than L-TRP, which suggests that L-TRP is more resistant to the voltage changes. This indicates that NPGB favors stronger interactions with L-TRP than DTRP. It is of note that as $\mathrm{V}_{\text {applied }}$ decreases from $-0.2 \mathrm{~V}$ to $0.0 \mathrm{~V}$, the ratio for L-TRP suddenly decreases rapidly and both TRP enantiomers display similar peak intensity ratios. This indicates that the applied voltage is no longer sufficient to promote enantiospecific TRP-NPGB interactions since the TRP molecules are no longer in close proximity to the asymmetric interaction sites. 

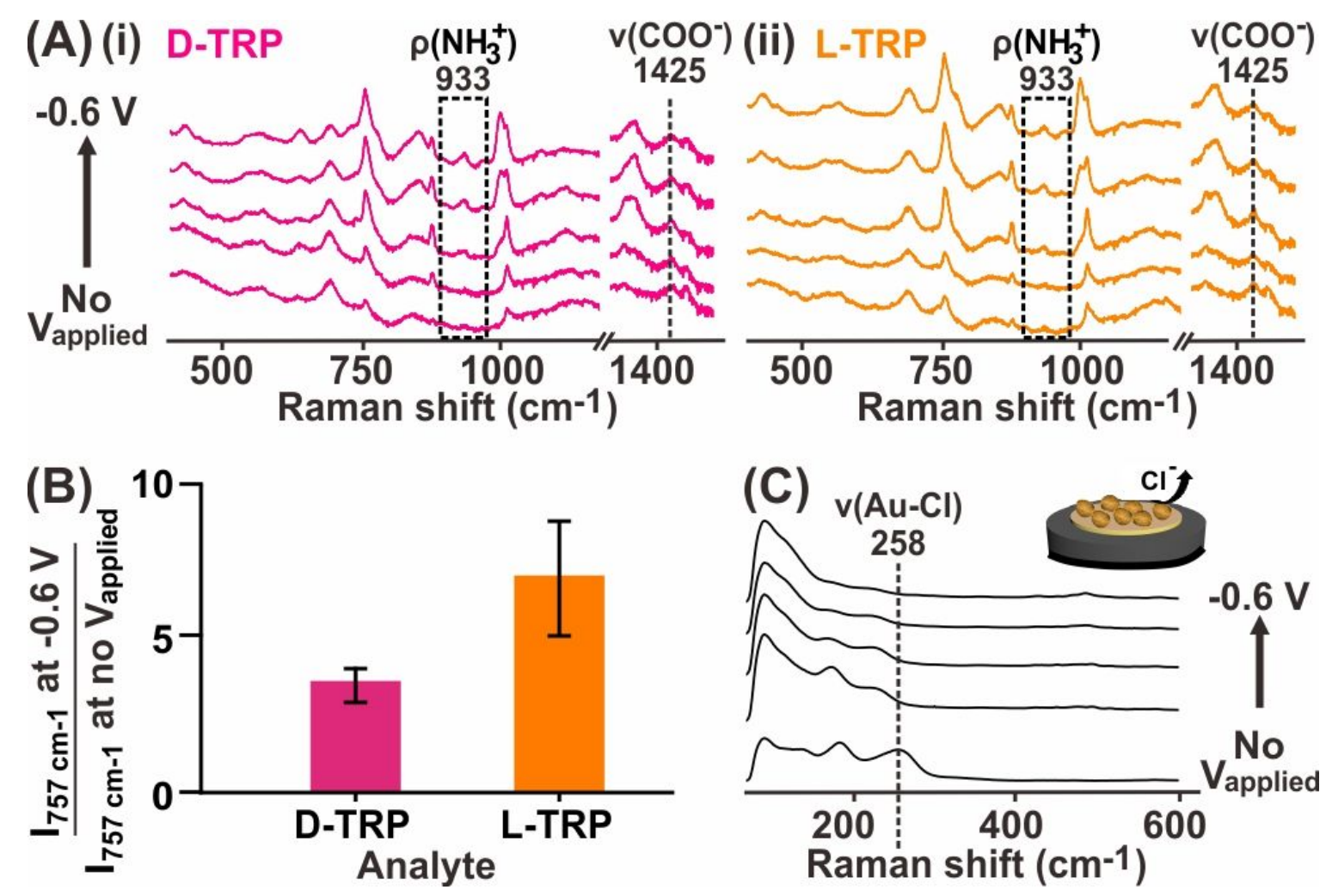

Figure S10. Investigating the potential-dependent SERS spectra variations. (A) Potentialdependent SERS spectra evolution of (i) D-TRP and (ii) L-TRP with increasingly negative $V_{\text {applied, }}$, at $-0.2 \mathrm{~V}$ intervals. (B) Decrease in Au-Cl stretching intensity at $258 \mathrm{~cm}^{-1}$ with $\mathrm{V}_{\text {applied. }}$

To gain insight on the variation in SERS intensity as the adsorption strength and orientation changes we studied the SERS spectra at different $V_{\text {applied }}$ because the differences in molecule-NPG interactions are amplified when a potential is applied. In the initial TRP spectra at no $\mathrm{V}_{\text {applied, }}$, the comparatively stronger carboxylate vibration mode at $1425 \mathrm{~cm}^{-1}$ compared to those of $\mathrm{NH}_{3}^{+}$(expected at $\sim 933 \mathrm{~cm}^{-1}$, indexed to $\mathrm{NH}_{3}{ }^{+}$rocking) suggests that both TRP enantiomers primarily adsorb through their carboxylate moieties without $\mathrm{V}_{\text {applied, }}$ via physisorption (Figure $\mathrm{S} 10 \mathrm{~A}$ ). With $\mathrm{V}_{\text {applied, }}$, the enhancement of $\mathrm{NH}_{3}{ }^{+}$related vibrational modes $\left(852\right.$ and $933 \mathrm{~cm}^{-1}$, indexed to $\mathrm{NH}_{3}^{+}$bending and rocking respectively) and the consistent observation of carboxylate and indole-associated vibrational modes enable us to conclude that TRP undergoes a potential-induced reorientation to interact via the carboxylate, amino and indole ring moieties (Figure S10A).

We also observe a general increase in SERS peak intensities with $\mathrm{V}_{\text {applied, }}$, relative to the intensities observed at no $\mathrm{V}_{\text {applied }}$ (Figure $\mathrm{S} 10 \mathrm{~B}$ ). We attribute this to the composite influence from several factors including 1) electromagnetic and/or chemical enhancement, ${ }^{14}$ 2) electrochemical desorption of interfering capping agents from the surface and 3) surface charge manipulation to increase surface coverage of the analyte. The desorption of interfering $\mathrm{Cl}^{-}$anions (present as electrolyte ions) from the NPGB surface is evidenced by the decrease in Au-Cl peak intensity at $258 \mathrm{~cm}^{-1}$ (Figure 
S10C). ${ }^{15,16}$ Such heightened SERS sensitivity is essential for direct elucidation of TRP molecular fingerprint to probe enantiospecific spectral changes. More importantly, we also observe that the SERS signals are enhanced to different extents between the two enantiomers, which are likely due to the differential adsorption affinities and orientations of the two enantiomers. In particular, the $757 \mathrm{~cm}^{-1}$ peak intensity increases by 7-fold and 3-fold at $\mathrm{V}_{\text {applied }}=-0.6 \mathrm{~V}$, for L- and D-TRP respectively (Figure $\mathrm{S} 10 \mathrm{~B})$. However, it is of note that the overall changes in SERS enhancement is due to the cumulative effect of several factors occurring simultaneously and thus, we cannot isolate their individual contributions. Nonetheless, we utilize the overall electrochemically enhanced SERS spectra to facilitate our label-free chiral SERS sensing. 

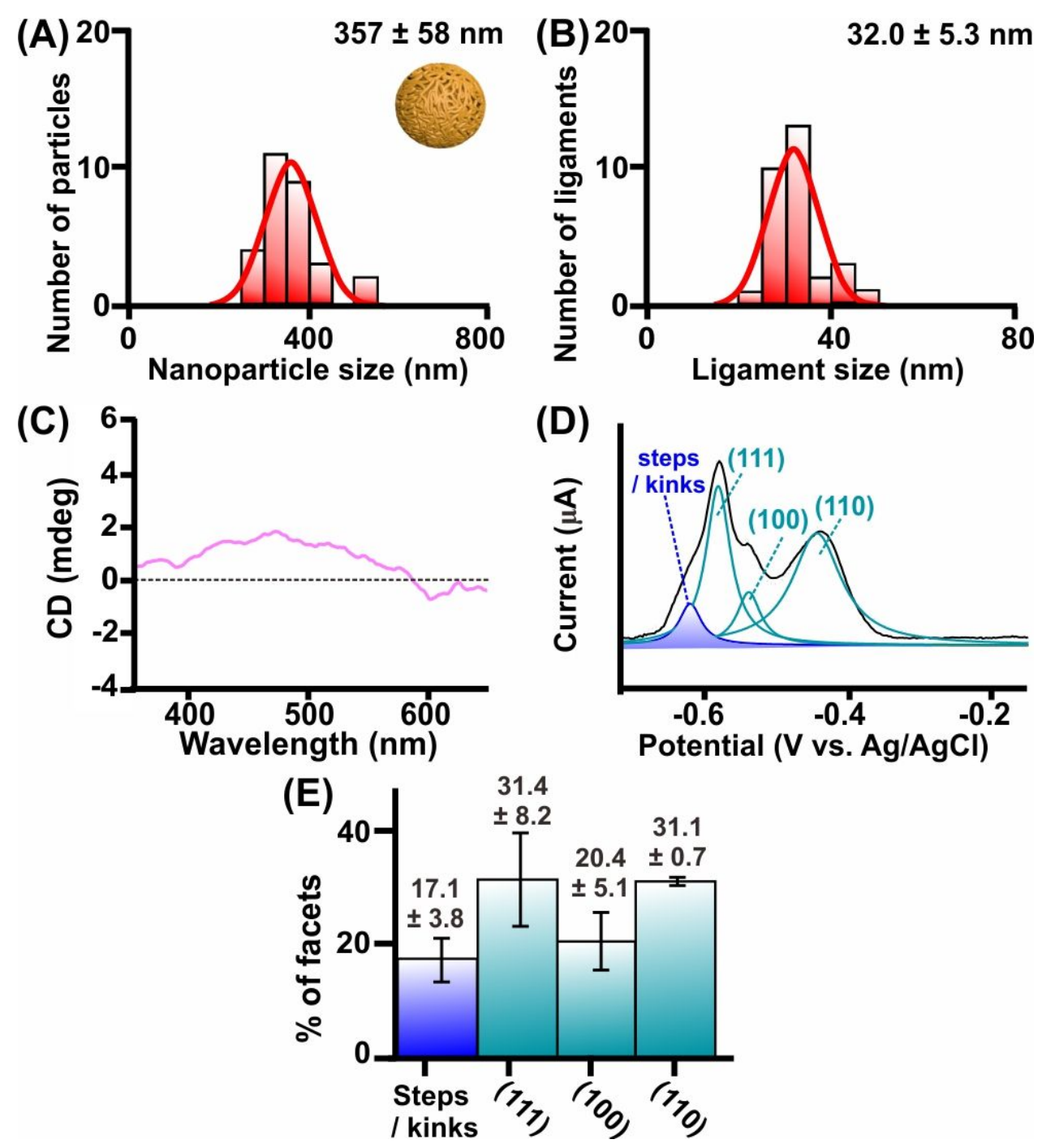

Figure S11. Characterization of nanoporous gold spheres (NGSs). (A, B) NGS nanoparticle size and ligament size distribution curve. (C) Circular dichroism spectrum of NGS. (D-E) $\mathrm{Pb}$ underpotential deposition cyclic voltammogram of NGS, conducted in deoxygenated solutions of 1 $\mathrm{mM} \mathrm{Pb}\left(\mathrm{NO}_{3}\right)_{2}$ in $0.1 \mathrm{M} \mathrm{NaOH}$ at $2 \mathrm{mV} \mathrm{s}^{-1}$ scan rate. (D) Deconvolution of the stripping waves into the component peaks and (E) relative \% of each facet/defect. Average and standard deviations are obtained from 3 measurements. 
(A)

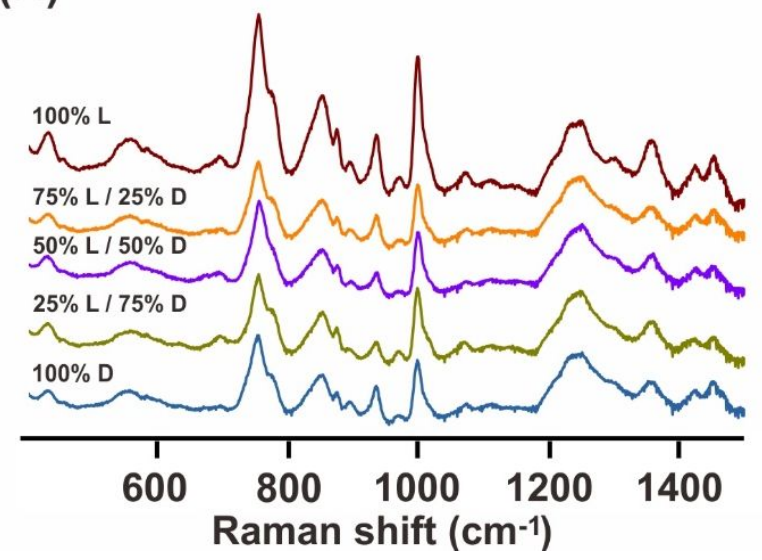

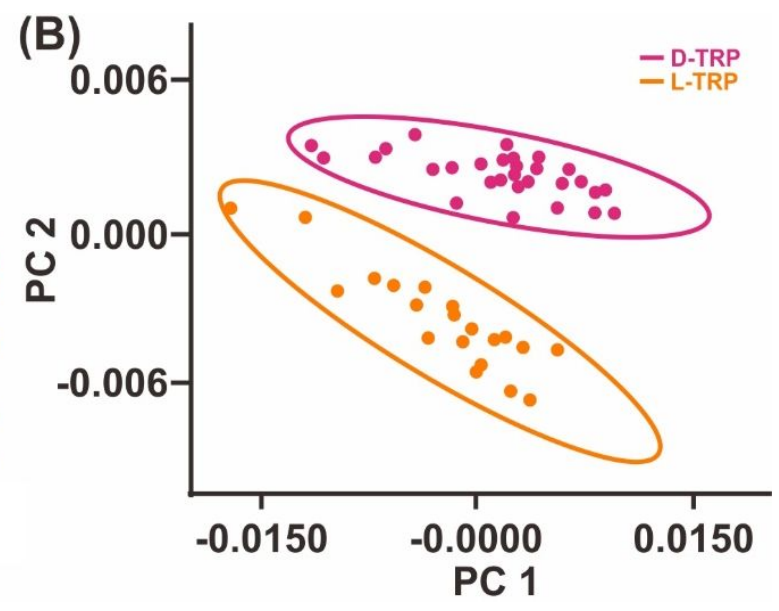

Figure S12. (A) SERS spectra of composite L-/D-TRP mixtures used to construct PLS calibration curve. (B) PCA score plot of $10 \mathrm{mM}$ D-TRP and L-TRP.

It is of note that the PLS calibration model was constructed from SERS spectra collected at lower concentrations of 2 to $10 \mathrm{mM}$ to prevent TRP co-precipitation. Consequently, the new bands at 643 $\mathrm{cm}^{-1}$ and $731 \mathrm{~cm}^{-1}$ are not as enhanced. Nonetheless, we would like to highlight that even though the spectra appear similar by visual inspection, the use of chemometric tools enables us to readily detect subtle spectral differences. Notably, PCA analysis of the SERS spectra collected at lower concentrations still show distinct, well-separated clusters corresponding to each enantiomer, with 95\% of confidence level (Figure S12B). This affirms that the corresponding L-/ D-TRP spectra are indeed statistically different from each other, highlighting that there are sufficient differentiating points between the two spectra to enable the separation. 

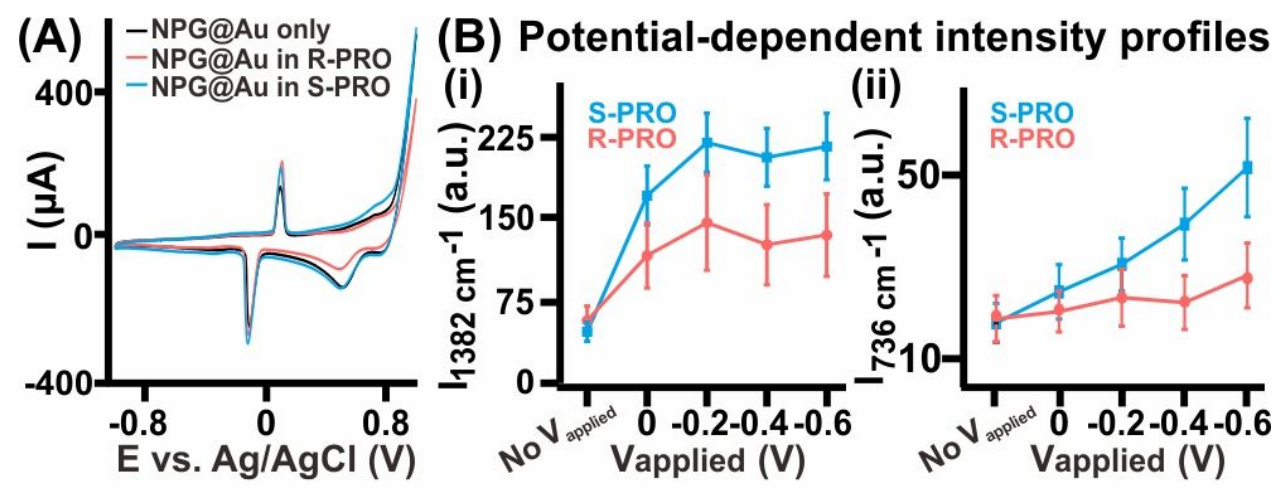

(C) Control experiments using smooth Au NPs
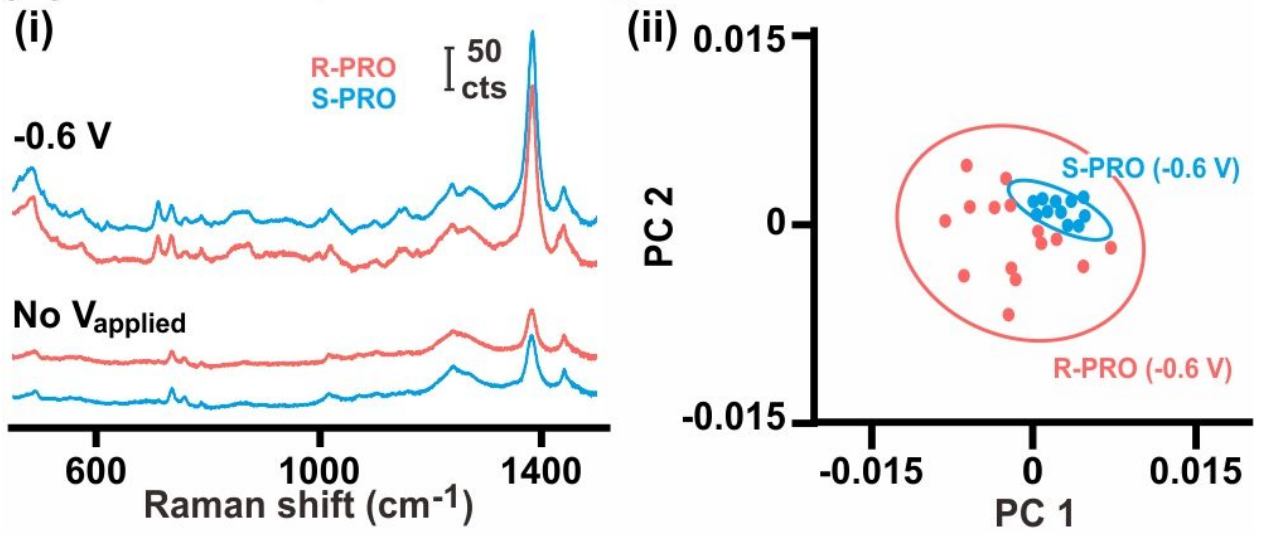

(D)

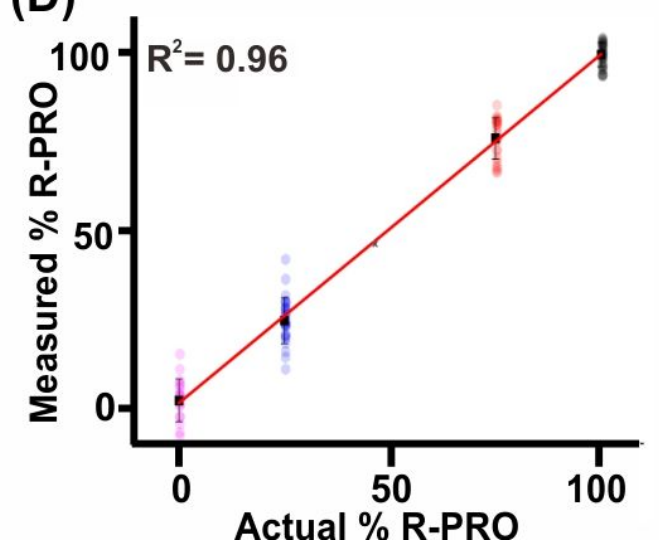

Figure S13. Chiral differentiation of propranolol (PRO) enantiomers. (A) Cyclic voltammograms of NPGB-modified electrode (NPGB@Au) with and without R- and S-PRO using $0.1 \mathrm{M} \mathrm{KCl}$ as electrolyte. We eliminate the possibility of electrochemical reduction of PRO due to the negligible increase in faradaic current with PRO addition. (B) Potential-dependent peak intensity profiles of two selected peaks at (i) $1382 \mathrm{~cm}^{-1}$ and (ii) $736 \mathrm{~cm}^{-1}$ for R- and S-PRO. Averages and standard deviations were obtained from 12 spectra. The SERS signals of S-PRO are significantly more enhanced than that of R-PRO with more negative $\mathrm{V}_{\text {applied }}$, suggesting that S-PRO has higher adsorption affinity to NPGB than R-PRO. (C) (i) SERS spectra of PRO enantiomers obtained without and at $\mathrm{V}_{\text {applied }}=-0.6 \mathrm{~V}$ using smooth spherical Au NPs and (ii) corresponding PCA score plot (PC 1 vs. PC 2). (D) PLS regression plot of measured against actual \% R-PRO. The calibration curve is constructed from spectra collected in varying $\% \mathrm{R} / \mathrm{S}-\mathrm{PRO}$ mixtures at $50 \mathrm{mM}$ total [PRO]. 
Table S5. PRO peak assignment without and with negative applied potential, $\mathbf{V}_{\text {applied }}$.

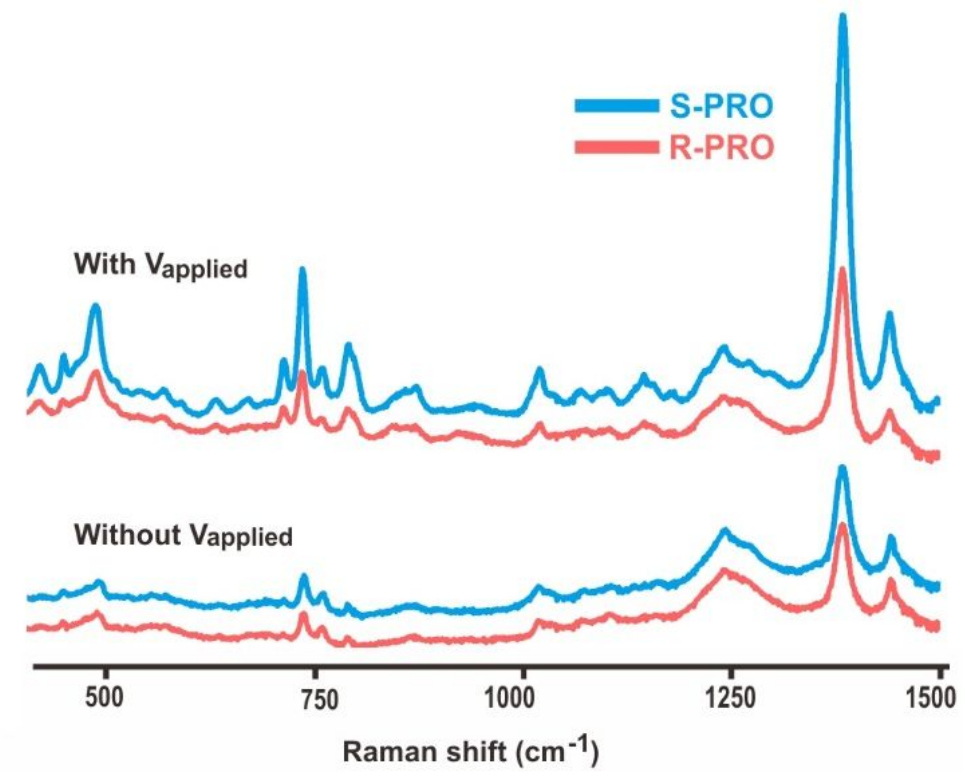

\begin{tabular}{|c|c|c|c|}
\hline $\begin{array}{r}\text { Experime } \\
\text { shift }\end{array}$ & $\begin{array}{l}\text { Raman } \\
\left.\mathbf{1}^{-1}\right)\end{array}$ & $\begin{array}{l}\text { Literature values } \\
\qquad\left(\mathrm{cm}^{-1}\right)\end{array}$ & Peak assignment ${ }^{17-18}$ \\
\hline $\begin{array}{l}\text { Without } \\
\mathrm{V}_{\text {applied }}\end{array}$ & $\mathbf{V}_{\text {applied }}$ & & \\
\hline- & 421 & 423 & Out of plane deformation naphthyl $+\rho\left(\mathrm{CH}_{3}\right)$ \\
\hline 490 & & 491 & Symmetric longitudinal stretching naphthyl \\
\hline- & 576 & 518 & $\delta(\mathrm{CCC})$ naphthyl \\
\hline- & 633 & 621 & Out of plane deformation naphthyl \\
\hline- & 665 & 667 & $\delta(\mathrm{CCC})$ naphthyl \\
\hline $\begin{array}{l}710 \\
736\end{array}$ & & 736 & Naphthyl breathing \\
\hline 759 & & 757 & $v\left(\mathrm{C}-\mathrm{CH}_{3}\right)+v(\mathrm{CNC})$ \\
\hline 789 & & 789 & Naphthyl out of plane deformation \\
\hline- & 815 & 818 & $v(\mathrm{CCC})_{\mathrm{CH} 3}+\delta(\mathrm{NH})$ \\
\hline- & 842 & & \\
\hline- & 872 & 869 & $\rho\left(\mathrm{CH}_{3}\right)+\rho\left(\mathrm{CH}_{2}\right)$ \\
\hline 1019 & & 1018 & $v(\mathrm{CC})+\rho\left(\mathrm{NH}_{2}\right)$ \\
\hline $\begin{array}{c}1033 \\
\text { (shoulder) }\end{array}$ & & 1027 & $\delta(\mathrm{OH})+\rho\left(\mathrm{CH}_{2}\right)$ \\
\hline 1072 & & 1068 & $\begin{array}{c}\delta(\mathrm{CCC}) \text { naphthyl }+v(\mathrm{CC}) \text { methylethylamino } \\
\text { chain }\end{array}$ \\
\hline 1104 & & 1098 & $v(\mathrm{CO})+\delta(\mathrm{CCC})$ \\
\hline
\end{tabular}




\begin{tabular}{ccc}
\hline 1145 & 1159 & $\delta\left(\mathrm{C}-\left(\mathrm{CH}_{3}\right)_{2}\right)+\tau\left(\mathrm{CH}_{2}\right)+\tau\left(\mathrm{NH}_{2}\right)+\beta(\mathrm{CH})$ \\
1160 & 1178 & \\
\hline 1241 & 1240 & $\tau\left(\mathrm{CH}_{2}\right)+\tau\left(\mathrm{NH}_{2}\right)+\delta(\mathrm{CH})+\beta(\mathrm{OH})$ \\
1253 & 1273 & methylethylamino chain \\
1267 & & \\
\hline 1383 & 1382 & $v(\mathrm{CC})$ naphthyl $+\delta(\mathrm{CH})+\omega\left(\mathrm{CH}_{2}\right)$ \\
\hline 1441 & 1440 & $\delta(\mathrm{CH})$ naphthyl $+\omega\left(\mathrm{NH}_{2}\right)$ \\
\hline 1508 & 1503 & Methylethylamino chain vibrations \\
\hline
\end{tabular}




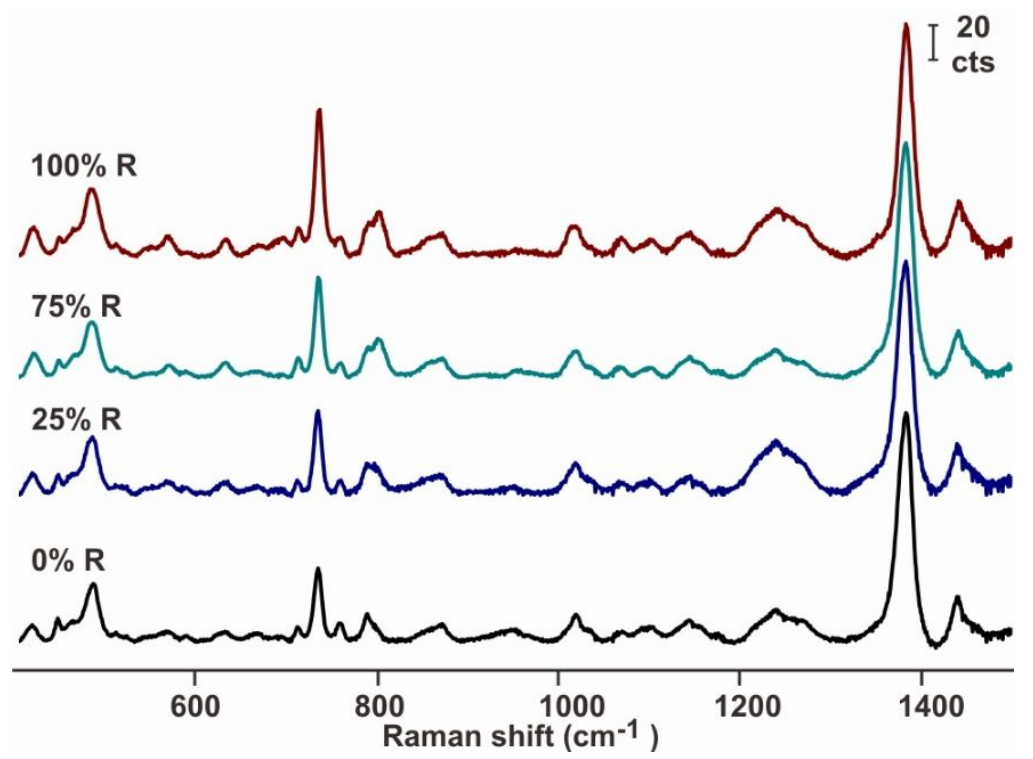

Figure S14. Representative SERS spectra of composite R-/S-PRO mixtures used to construct the PLS calibration curve. 


\section{References}

1. Berova, N.; Bari, L. D.; Pescitelli, G., Application of Electronic Circular Dichroism in Configurational and Conformational Analysis of Organic Compounds. Chem. Soc. Rev. 2007, 36, 914931.

2. Schäferling, M., Back Matter In Chiral Nanophotonics: Chiral Optical Properties of Plasmonic Systems, Springer International Publishing: Cham, 2017; pp 141-159.

3. González-Rubio, G.; Mosquera, J.; Kumar, V.; Pedrazo-Tardajos, A.; Llombart, P.; Solís, D. M.; Lobato, I.; Noya, E. G.; Guerrero-Martínez, A.; Taboada, J. M.; Obelleiro, F.; MacDowell, L. G.; Bals, S.; Liz-Marzán, L. M., Micelle-Directed Chiral Seeded Growth on Anisotropic Gold Nanocrystals. Science 2020, 368, 1472.

4. $\quad$ Lee, H.-E.; Ahn, H.-Y.; Mun, J.; Lee, Y. Y.; Kim, M.; Cho, N. H.; Chang, K.; Kim, W. S.; Rho, J.; Nam, K. T., Amino-Acid- and Peptide-Directed Synthesis of Chiral Plasmonic Gold Nanoparticles. Nature 2018, 556, 360-365.

5. Guerrero-Martínez, A.; Alonso-Gómez, J. L.; Auguié, B.; Cid, M. M.; Liz-Marzán, L. M., From Individual to Collective Chirality in Metal Nanoparticles. Nano Today 2011, 6, 381-400.

6. Auguié, B.; Alonso-Gómez, J. L.; Guerrero-Martínez, A.; Liz-Marzán, L. M., Fingers Crossed: Optical Activity of a Chiral Dimer of Plasmonic Nanorods. J. Phys. Chem. Lett. 2011, 2, 846-851.

7. $\quad \mathrm{Hu}, \mathrm{Z}$;; Meng, D.; Lin, F.; Zhu, X.; Fang, Z.; Wu, X., Plasmonic Circular Dichroism of Gold Nanoparticle Based Nanostructures. Adv. Opt. Mater. 2019, 7, 1801590.

8. Hebié, S.; Cornu, L.; Napporn, T. W.; Rousseau, J.; Kokoh, B. K., Insight on the Surface Structure Effect of Free Gold Nanorods on Glucose Electrooxidation. J. Phys. Chem. C 2013, 117, 9872-9880.

9. Hussain, S.; Pang, Y., Surface Geometry of Tryptophan Adsorbed on Gold Colloidal Nanoparticles. J. Mol. Struct. 2015, 1096, 121-128.

10. Aliaga, A. E.; Osorio-Román, I.; Leyton, P.; Garrido, C.; Cárcamo, J.; Caniulef, C.; Célis, F.; Díaz F, G.; Clavijo, E.; Gómez-Jeria, J. S.; Campos-Vallette, M. M., Surface-Enhanced Raman Scattering Study of L-Tryptophan. J. Raman Spectrosc. 2009, 40, 164-169.

11. Maiti, N.; Thomas, S.; Jacob, J. A.; Chadha, R.; Mukherjee, T.; Kapoor, S., DFT and SurfaceEnhanced Raman Scattering Study of Tryptophan-Silver Complex. J. Colloid Interface Sci. 2012, 380, 141-149.

12. Laurentius, L.; Stoyanov, S. R.; Gusarov, S.; Kovalenko, A.; Du, R.; Lopinski, G. P.; McDermott, M. T., Diazonium-Derived Aryl Films on Gold Nanoparticles: Evidence for a CarbonGold Covalent Bond. ACS Nano 2011, 5, 4219-4227.

13. Han, X.; Lee, H. K.; Lee, Y. H.; Hao, W.; Liu, Y.; Phang, I. Y.; Li, S.; Ling, X. Y., Identifying Enclosed Chemical Reaction and Dynamics at the Molecular Level Using Shell-Isolated Miniaturized Plasmonic Liquid Marble. J. Phys. Chem. Lett. 2016, 7, 1501-1506.

14. Wu, D.-Y.; Li, J.-F.; Ren, B.; Tian, Z.-Q., Electrochemical Surface-Enhanced Raman Spectroscopy of Nanostructures. Chem. Soc. Rev. 2008, 37, 1025-1041.

15. Tadayyoni, M. A.; Weaver, M. J., Adsorption and Electrooxidation of Carbon Monoxide at the Gold-Aqueous Interface Studied by Surface-Enhanced Raman Spectroscopy. Langmuir 1986, 2, 179183.

16. Greene, B. H. C.; Alhatab, D. S.; Pye, C. C.; Brosseau, C. L., Electrochemical-Surface Enhanced Raman Spectroscopic (EC-SERS) Study of 6-Thiouric Acid: A Metabolite of the Chemotherapy Drug Azathioprine. J. Phys. Chem. C 2017, 121, 8084-8090.

17. Stiufiuc, R.; Iacovita, C.; Stiufiuc, G.; Bodoki, E.; Chis, V.; Lucaciu, C. M., Surface Mediated Chiral Interactions between Cyclodextrins and Propranolol Enantiomers: A SERS and DFT Study. Phys. Chem. Chem. Phys. 2015, 17, 1281-1289.

18. Stiufiuc, R.; Iacovita, C.; Lucaciu, C. M.; Stiufiuc, G.; Nicoara, R.; Oltean, M.; Chis, V.; Bodoki, E., Adsorption Geometry of Propranolol Enantiomers on Silver Nanoparticles. J. Mol. Struct. 2013, 1031, 201-206. 